\title{
Core-Shell-Structured Highly Branched Poly(ethylenimine amide)s: Synthesis and Structure
}

\author{
Lydie Antonietti, ${ }^{\dagger}$ Cyril Aymonier, ${ }^{\ddagger}$ Ulf Schlotterbeck, ${ }^{\ddagger}$ Vasil M. Garamus, ${ }^{\S}$ \\ Tatiana Maksimova, ${ }^{\perp}$ Walter Richtering, ${ }^{\perp}$ and Stefan Mecking*, ${ }^{*}$ \\ Fachbereich Chemie, Universität Konstanz, D-78457 Konstanz, Germany; Institut für \\ Makromolekulare Chemie und Freiburger Materialforschungszentrum der Albert-Ludwigs-Universität \\ Freiburg, Stefan-Meier-Str. 31, D-79104 Freiburg, Germany; GKSS Research Centre, Max Planck Str., \\ D-21502 Geesthacht, Germany; and Institut für Physikalische Chemie, RWTH Aachen, \\ Templergraben 59, D-52056 Aachen, Germany
}

\begin{abstract}
The synthesis of amphiphilic macromolecules by amidation of hyperbranched polyethylenimine was studied. Amidation with palmitic acid or the methyl ester proceeds up to $84 \%$ degree of amidation $\left(140^{\circ} \mathrm{C}\right.$, vacuum). The primary amine end groups react preferentially. With carbonyldiimidazole (CDI)-activated acids nearly complete conversion of all primary amine end groups and secondary amine linear units can be achieved; with a corresponding limited amount of CDI the end groups can be amidated selectively. The products of these reactions are free of any unreacted carboxylic acid or other impurities $\left({ }^{1} \mathrm{H}\right.$ and $\left.{ }^{13} \mathrm{C} \mathrm{NMR}\right)$ and can be optionally purified by pressure ultrafiltration washing with a toluene/ amine solution. Side-chain crystallization is observed (DSC), which can be supressed entirely employing branched alkyl moieties (2-hexyldecanoic acid as amidating agent). Solution structures were studied by SANS. In $\mathrm{C}_{6} \mathrm{D}_{6}$ radii of gyration of $2-5 \mathrm{~nm}$ (Guinier analysis) were observed for samples differing in PEI core molecular weight. These sizes and their observed independence of concentration in the range of 5-40 $\mathrm{g} \mathrm{L}^{-1}$ indicate the presence of nonaggregated unimolecular inverted micelles.
\end{abstract}

\section{Introduction}

Defined micellar structures are of interest from a fundamental perspective, as well as for applications. For example, such structures can be used as hosts for the encapsulation and subsequent controlled release of guest molecules ${ }^{1}$ or as templates for the formation of nanoscale particles. ${ }^{2}$ Block copolymer micelles can allow for a precise control of metal nanoparticle size and arrangement in thin films. ${ }^{3}$ However, such self-assembled micelles are by their nature dynamic in solution, and they can be shear sensitive. Therefore, unimolecular polymeric micelles are of interest for particle formation and stabilization. ${ }^{4}$ For particle size control, polymeric micelles of defined structure are required. Polymer-analogous amphiphilic modification of a highly branched scaffold represents a convenient route, if a scaffold of defined molecular weight distribution, branching, and chemical structure is utilized in combination with effective modification reactions. We have investigated hybrids of amphiphilically modified hyperbranched polyglycerols ${ }^{5,6}$ with metal nanoparticles as soluble catalysts for hydrogenation and $\mathrm{C}-\mathrm{C}$ coupling reactions. ${ }^{7}$ Polyethylenimines (PEI) represent another class of readily available, highly branched molecules. ${ }^{8}$ By comparison to modified polyglycerols (polyether polyols), such polyamines will coordinate much more strongly to metal salts or other precursors used for metal particle synthesis and also to the surface of the final metal nanoparticles. Amidation of PEI with apolar aliphatic acid derivatives can afford polymers that are soluble in apolar organic solvents. Silver nanoparticles stabilized

\footnotetext{
$\dagger$ Universität Konstanz.

Albert-Ludwigs-Universität Freiburg.

$\S$ GKSS Research Centre.

${ }^{\perp}$ RWTH Aachen.

* To whom correspondence should be addressed. E-mail: stefan.mecking@uni-konstanz.de.
}

by such amphiphilic poly(ethylenimine amide)s (PEIamides) possess antimicrobial properties. ${ }^{9}$ The PEIamide can act as a unimolecular "nanoreactor" for the synthesis of a silver particle. ${ }^{10}$ Despite their apparent attractiveness due to their accessibility from cheap starting materials, the synthesis of amphiphilic poly(ethylenimine amide)s and characterization with respect to microstructure have not been reported to date. Also, solution structures have not been studied. Because of their amphiphilicity, these hyperbranched polymers could form aggregates in solution. SANS studies were carried out in dilute solutions to this end.

\section{Results and Discusssion}

Polymer Synthesis and Characterization. Polyethylenimine is prepared by cationic ring-opening polymerization of aziridine on a large scale. Depending on the reaction conditions, linear or highly branched products can be obtained. ${ }^{11}$ For the present study, commercially available highly branched polyethylenimine (PEI) was employed.

The material contains primary amine end groups, secondary amine linear units, and tertiary amine branched (i.e., dendritic) units in a 34:36:30 ratio for PEI with a molecular weight of $M_{\mathrm{w}} 5000 \mathrm{~g} \mathrm{~mol}^{-1}$ and in a 31:39:30 ratio for PEI with a molecular weight of $M_{\mathrm{w}}$ $25000 \mathrm{~g} \mathrm{~mol}^{-1}$, as determined by inverse gated ${ }^{13} \mathrm{C} \mathrm{NMR}$ spectroscopy (relaxation time $=4 \mathrm{~s}$ ). These values are similar to data previously published for branched polyethylenimine. ${ }^{12}$ The degree of branching (DB) of these polymers can be defined as $\mathrm{DB}=2 D /(2 D+L)(D=$ dendritic units; $L=$ linear units). ${ }^{13}$ The values obtained by inverse gated ${ }^{13} \mathrm{C} \mathrm{NMR}$ spectroscopy correspond to a degree of branching of 63 and $61 \%$, respectively, by comparison to $100 \%$ for a perfect dendrimer and $0 \%$ for a linear polymer. For the introduction of apolar hydrophobic functionalities, amidation ${ }^{14}$ with long-chain car- 
Scheme 1. Functionalization of Polyethylenimine with Palmitic Acid Derivatives $(X=O H$, OMe, or $\mathbf{C}_{3} \mathbf{H}_{3} \mathbf{N}_{2}, \mathbf{R}=\mathbf{C}_{15} \mathbf{H}_{31}$; Depicted as an Example: Limited Conversion Due to Limited Amount of Reagent $\mathbf{X}-\mathbf{C}(=\mathbf{O})-\mathbf{R})$

Polyethyleneimine (PEI)
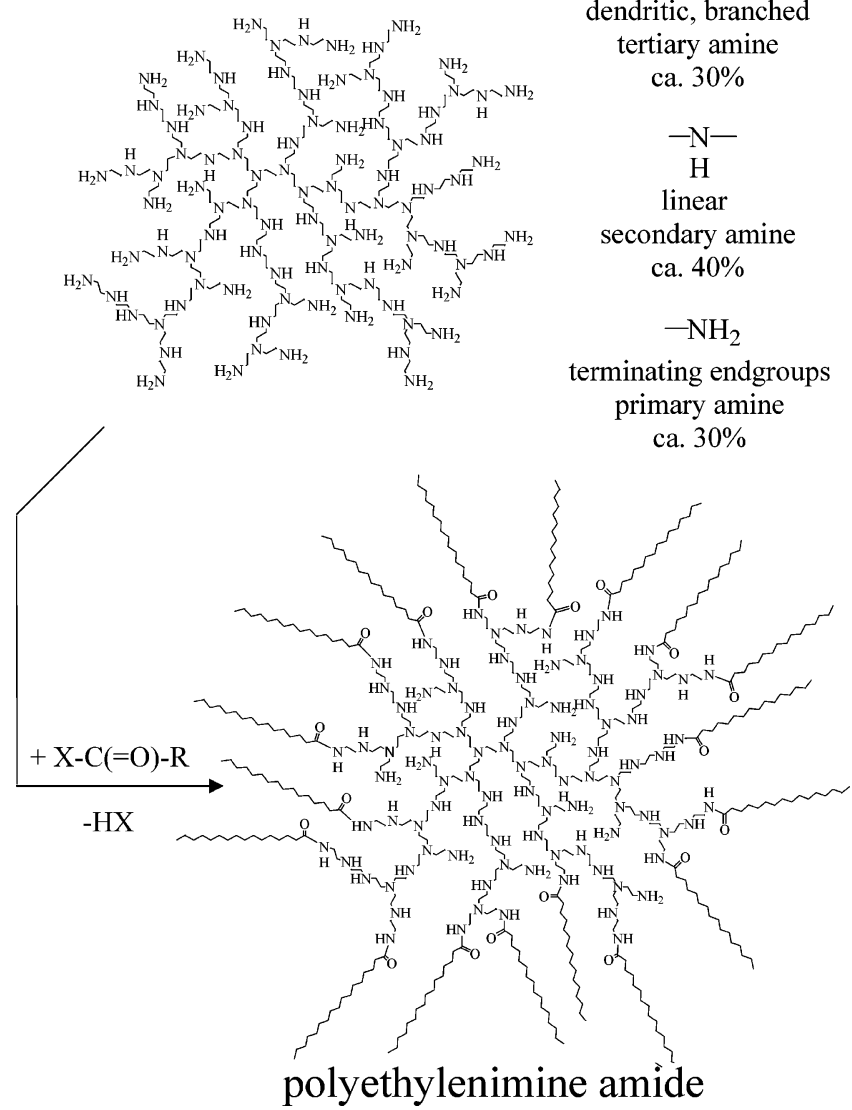

boxylic acid or acid derivatives was chosen (Scheme 1). Meijer et al. have described the reaction of polypropylenimine dendrimers (ideally containing only tertiary amine branched moieties and primary amine terminal groups) with fatty acid chlorides, using a large excess of $\mathrm{NEt}_{3}$ as a base. ${ }^{15}$ As a general consideration, all reactions involving excess carboxylic acid as a reagent, or forming acidic byproducts (e.g., $\mathrm{HCl}$ in reactions of acid chlorides), will result in ammonium salt formation with the basic PEI. Removal requires the addition of base and must be monitored carefully in order to obtain defined products.

The maximum extent of the reaction that is possible would be full conversion of $-\mathrm{NH}_{2}$ to $-\mathrm{NH}(\mathrm{CO}) \mathrm{R}$ and of $-\mathrm{NH}-$ to $-\mathrm{N}(\mathrm{CO}) \mathrm{R}-$. Degrees of amidation and equivalents of acids used as a reagent are discussed on this basis. PEI-amides are abbreviated as PEI5K/ $25 \mathrm{Kam}{ }^{\mathrm{lin} / \mathrm{br}} \mathrm{C} 16_{\mathrm{DA}}$, where $5 \mathrm{~K}$ and $25 \mathrm{~K}$ correspond to the core molecular weight of the polymer $\left(M_{\mathrm{w}} 5000\right.$ and $25000 \mathrm{~g} \mathrm{~mol}^{-1}$, respectively); lin indicates that PEI was modified with palmitic acid or methyl palmitate, whereas br refers to a modification with 2-hexyldecanoic acid and DA corresponds to the degree of amidation.

Stirring the highly viscous, liquid PEI with $0.43-1$ equiv of palmitic acid $\left(\mathrm{mp}=61{ }^{\circ} \mathrm{C}\right)$ results in a heterogeneous mixture. Upon heating to $140{ }^{\circ} \mathrm{C}$, stirring for $1 \mathrm{~h}$ at this temperature a homogeneous mixture is obtained, such that mass transfer is not an issue. ${ }^{16}$

The reaction of PEI $5 \mathrm{~K}$ with 0.35 equiv of palmitic acid, which is slightly less than the amount required to

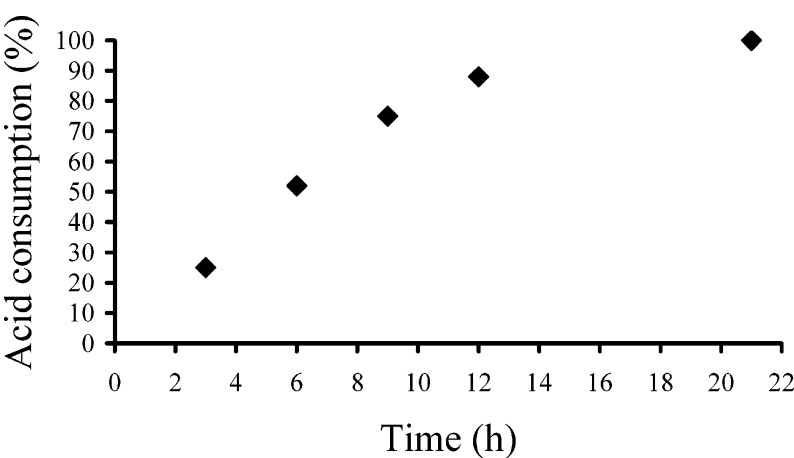

Figure 1. Acid consumption over time. Reaction conditions: $2.00 \mathrm{~g}$ of PEI $5 \mathrm{~K} ; 2.98 \mathrm{~g}$ of palmitic acid ( 0.35 equiv); $140{ }^{\circ} \mathrm{C}$; 17 mbar.

react all primary amines groups (0.43 equiv), was monitored by ${ }^{13} \mathrm{C}$ NMR spectroscopy (Figure 1). The reaction goes to completion over the course of $21 \mathrm{~h}$.

Any residual unreacted acid potentially present in the crude product can be detected by ${ }^{13} \mathrm{C}$ NMR spectroscopy: the carbonyl resonance of the free carboxylic acid, as well as the resonance of the carbonyl function of the alkylammonium carboxylate salt formed by mixing PEI and the carboxylic acid, occurs around $180 \mathrm{ppm}$ and can clearly be distinguished from that of the desired PEIamide at $173-174 \mathrm{ppm}$. Crude products were ultrafiltered in toluene prior to their analysis by NMR spectroscopy. ${ }^{13} \mathrm{C}$ NMR spectroscopy revealed the presence of carboxylic acid and carboxylate, in some cases. Presumably, the formation of carboxylate salt with the PEI prevents removal during the filtration. By adding $10 \mathrm{vol} \%$ of $\mathrm{NBu}_{3}$ to the toluene during ultrafiltration, complete removal of the excess acid could be achieved, however. Monitoring the composition of the filtrate by evaporating the solvent and analyzing the residue by ${ }^{1} \mathrm{H}$ NMR spectroscopy shows that acid is washed out, but the polymer is retained, as anticipated.

The IR spectrum of the material obtained features the characteristic amide bands at 1645 and $1545 \mathrm{~cm}^{-1}$. However, IR spectroscopy is not suited for the detection of residual acid: whereas the peak of the free acid (1700 $\mathrm{cm}^{-1}$ ) is separated from the PEI-amide bands, the carbonyl band of carboxylate $\left(1550 \mathrm{~cm}^{-1}\right)$ overlaps with the amide band. A mixture of an acid-free pure PEIamide (vide supra) with 20 wt $\%$ of palmitic acid features a spectrum very similar to that of the pure PEIamide in the characteristic carbonyl region.

The overall degree of amidation can be calculated from the ${ }^{1} \mathrm{H}$ NMR spectra (Figure 2).

In the unmodified PEI, as well as in the PEI-amide, the signals of the $\mathrm{NCH}_{2} \mathrm{CH}_{2} \mathrm{~N}$ protons of the PEI backbone are found in the range of $2.4-4.0 \mathrm{ppm}$. The $\mathrm{NH}_{n}(n=1$ or 2$)$ amine protons occur as a broad singlet at $1.3 \mathrm{ppm}$ (which disappears upon shaking the $\mathrm{CDCl}_{3}$ solution of the polymer with $\mathrm{D}_{2} \mathrm{O}$ ). The chemical shift of $\mathrm{NH}$ protons is known to vary strongly with the measurement conditions (concentration, temperature, solvent, etc.) and the molecular structure. In the PEIamide, the resonance of the protons of residual unreacted secondary or primary amine groups was concluded to coincide with the $\mathrm{NCH}_{2} \mathrm{CH}_{2} \mathrm{~N}$ backbone signals: a comparison of the integrals of the different resonances of the $\mathrm{C}_{15}$ alkyl chains gives no indication of underlying signals. The ratio of alkyl chains introduced per amine moiety (primary, secondary, and tertiary) in the starting PEI is $x=A /[P /(5-x)](A=$ integral for one proton of 

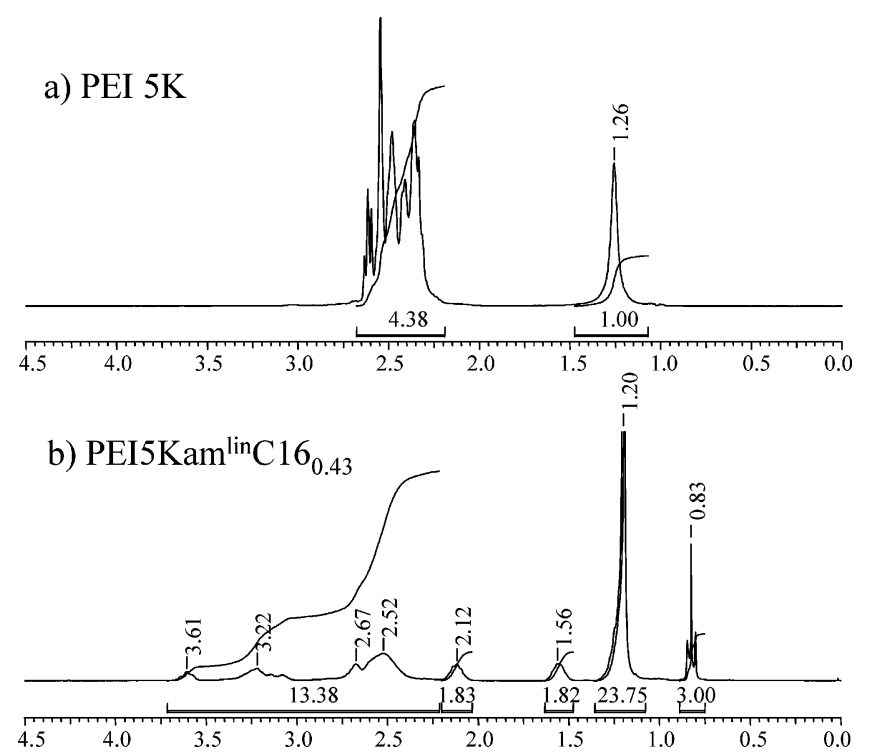

Figure 2. ${ }^{1} \mathrm{H}$ NMR spectra of polyethylenimine $M_{\mathrm{w}} 5000 \mathrm{~g}$ $\mathrm{mol}^{-1}$ (PEI 5K) (a) and amidated polyethylenimine with palmitic acid (PEIam5K ${ }^{\text {lin }}{ }^{2} 16_{0.43}$ ) (b) in $\mathrm{CDCl}_{3}$.

the alkyl chain as determined from signals of the $\mathrm{C}(=\mathrm{O}) \mathrm{CH}_{2} \mathrm{CH}_{2}$ groups, $P=$ integral of region 2.4-4.0 ppm) and can be calculated with a few iteration steps. As indicated previously, the degree of amidation is a more useful measure, $\mathrm{DA}=x(L+T+D) /(L+T)$.

For the reaction of PEI with palmitic acid as an amidating agent, in the experiments carried out a maximum degree of amidation of $84 \%$ was observed (Table 1, entries 1-4)

Elemental analysis obviously represents a simple, direct method for determination of the degrees of amidation. Results of $\mathrm{C}, \mathrm{N}$, and $\mathrm{H}$ analysis are in reasonable agreement with the results obtained by ${ }^{1} \mathrm{H}$ NMR spectroscopy. However, accuracy decreases with increasing degrees of amidation (as the elemental composition of the amphiphilic polymer varies only slightly with DA at higher DAs). Thus, elemental analysis is viable for determination of the degree of amidation up to ca. $60 \%$ DA (Table 1).

By comparison to the aforementioned amidation with acid, amidation by an ester offers the clear advantage that excess ester is much more straightforward to remove from the polymeric product as no carboxylate salts are formed. A mixture of PEI and methyl palmitate is liquified by slight heating $\left(\mathrm{mp}=28{ }^{\circ} \mathrm{C}\right)$, and a homogeneous mixture is again obtained by heating at $140{ }^{\circ} \mathrm{C}$ for $1 \mathrm{~h}$. Reaction of PEI with $0.43-1$ equiv of methyl palmitate at $140{ }^{\circ} \mathrm{C}$ under vacuum overnight and subsequent purification by ultrafiltration in toluene afforded the pure PEI-amide. Polymers with a DA ranging from 43 to $57 \%$ were prepared (Table 1, entries 5-7).

In reaction with the acid as well as with the ester, in all cases given in Table 1 only partial conversion of the amino groups occurs. With 0.43 equiv of amidating agent $(0.43$ equiv $=100 \%$ conversion of the primary amine groups if these react selectively; vide supra), no differences between acid and ester are observed. At higher ratios amidating agent/PEI, the acid results in somewhat higher degrees of amidation, as expected on the basis of general reactivity in amidations.

To achieve higher conversions, more reactive amidating agents are required. Acid chlorides are more reactive than acids and esters. However, removal of $\mathrm{HCl}$ formed as a side product from the PEI core might be complicated and, more important, difficult to monitor reliably, as already discussed. We have therefore investigated the amidation using carbonyldiimidazol-activated acids (Scheme 2). Imidazol formed as a side product was removed by ultrafiltration in toluene solution. PEIamide free of imidazol and acid or other undesired carbonyl compounds was obtained, as evidenced by NMR spectroscopy. The degree of amidation was determined to be $\mathrm{DA}=90 \%$ with a PEI with a molecular weight of $M_{\mathrm{w}} 25000 \mathrm{~g} \mathrm{~mol}^{-1}$ and $91 \%$ with PEI of a molecular weight of $M_{\mathrm{w}} 5000 \mathrm{~g} \mathrm{~mol}^{-1}$; that is nearly all the primary and secondary amine functions have been converted to the amide.

As for the amidation with acid or ester as an amidating agent, the molecular weight of the core (5000 or $25000 \mathrm{~g} \mathrm{~mol}^{-1}$ ) does not seem to have a significant influence on the reactivity.

${ }^{13} \mathrm{C}$ NMR spectroscopy (Figure 3) provided further insights into the structure of the amidated polyethylenimines. The characteristic amide carbonyl peaks were observed around $174 \mathrm{ppm}$, in good agreement with the carbonyl shift measured in the case of PPI dendrimers functionalized with palmitoyl chains. ${ }^{15}$ Secondary and tertiary amide have about the same shift in the polymer, as confirmed by comparative reactions with model compounds of lower molecular weights. Octylamine and dioctylamine were reacted with 1 equiv of CDI-activated palmitic acid. The carbonyl group of the secondary amide gives rise to a signal at $\delta=173.0 \mathrm{ppm}$, whereas for the carbonyl groups of the tertiary amide $\delta=172.7$ ppm. As expected, similar results were obtained with the two model compounds prepared under bulk conditions (palmitic acid as the amidating agent). As for the signals of the alkyl chains, a shift to lower field of the methylene groups in the $\alpha$ - and $\beta$-position of the carbonyl vs the starting acid, respectively, ester was observed as expected, with loss of intensity for these two peaks. Also in spectra recorded in inverse gated mode with relaxation agent and a delay of up to $10 \mathrm{~s}$, signal intensities are not suited for quantitative assessment: within an alkyl chain, the signals of carbon atoms closer to the PEI core $\left(\mathrm{C}^{2}, \mathrm{C}^{3}\right)$ are less intense than those at the chain end.

The assignment of the peaks of the PEI-scaffold region (between 38 and $60 \mathrm{ppm}$ ) was complicated by broad and partially overlapping signals, but key peaks were assigned. The disappearance of the signal $\mathrm{h}$ of the D- $\mathrm{CH}_{2}-\mathrm{CH}_{2}-\mathrm{NH}_{2}$ groups indicates that they are amidated completely. Disappearance of $\mathrm{b}$ and $\mathrm{e}$ of the $\mathrm{L}-\mathrm{CH}_{2}-\mathrm{CH}_{2}-\mathrm{NH}_{2}$ groups (that is $\mathrm{CH}_{2}-\mathrm{CH}_{2}-\mathrm{NH}-$ $\mathrm{CH}_{2}-\mathrm{CH}_{2}-\mathrm{NH}_{2}$ groups) indicates that the primary amine end groups and/or the secondary amine linear groups are amidated. In view of the aforementioned complete amidation of $\mathrm{D}-\mathrm{CH}_{2}-\mathrm{CH}_{2}-\mathrm{NH}_{2}$ groups, it appears that also the $\mathrm{L}-\mathrm{CH}_{2}-\mathrm{CH}_{2}-\mathrm{NH}_{2}$ primary amine end groups, which should not differentiate in reactivity very much from $\mathrm{D}-\mathrm{CH}_{2}-\mathrm{CH}_{2}-\mathrm{NH}_{2}$ groups, are also reacted completely. In view of the mediocre quality of the obtainable spectra, the statement of "complete conversion" is subject to an error of $5-10 \%$. Reactions with low molecular weight model compounds confirmed the higher reactivity of primary amines vs secondary amines under the reaction conditions. Amidation of octylamine and dioctylamine with 1 equiv of palmitic acid under identical conditions $\left(140{ }^{\circ} \mathrm{C}\right.$, vacuum) was 
Table 1. Synthesis and Composition of Polyethylenimine Amides ${ }^{a}$

\begin{tabular}{|c|c|c|c|c|c|c|}
\hline \multirow[b]{2}{*}{$\begin{array}{l}\text { entry } \\
\text { no. }\end{array}$} & \multicolumn{3}{|c|}{ reaction conditions } & \multicolumn{3}{|c|}{ results } \\
\hline & $\begin{array}{l}\text { polyethyleneimine core } \\
\text { mol wt }\left(\mathrm{g} \mathrm{mol}^{-1}\right)\end{array}$ & $\begin{array}{l}\text { amidating } \\
\text { reagent }\end{array}$ & equiv $^{a}$ & $\begin{array}{l}\text { deg of amidation } \\
\text { from }{ }^{1} \mathrm{H} \text { NMR }(\%)\end{array}$ & $\begin{array}{l}\text { deg of amidation from } \\
\text { elemental analysis }(\%)\end{array}$ & $\begin{array}{l}\text { melting } \\
\text { point }\left({ }^{\circ} \mathrm{C}\right)\end{array}$ \\
\hline 1 & 5000 & $\mathrm{HOOC}^{\operatorname{lin}} \mathrm{C}_{15} \mathrm{H}_{31}$ & 1 & 84 & $(62)^{b}$ & $30+64$ \\
\hline 2 & 5000 & $\mathrm{HOOC}^{\operatorname{lin}} \mathrm{C}_{15} \mathrm{H}_{31}$ & 0.71 & 70 & $(60)^{b}$ & $32+63$ \\
\hline 3 & 25000 & $\mathrm{HOOC}^{\operatorname{lin}} \mathrm{C}_{15} \mathrm{H}_{31}$ & 0.71 & 71 & $(58)^{b}$ & $37+59$ \\
\hline 4 & 5000 & $\mathrm{HOOC}^{\operatorname{lin}} \mathrm{C}_{15} \mathrm{H}_{31}$ & 0.43 & 43 & 42 & $41+64$ \\
\hline 5 & 5000 & $\mathrm{MeOOC}^{\operatorname{lin}} \mathrm{C}_{15} \mathrm{H}_{31}$ & 1 & 57 & 56 & $39+60$ \\
\hline 6 & 25000 & $\mathrm{MeOOC}^{\operatorname{lin}} \mathrm{C}_{15} \mathrm{H}_{31}$ & 1 & 56 & 53 & $40+63$ \\
\hline 7 & 5000 & $\mathrm{MeOOC}^{\operatorname{lin}} \mathrm{C}_{15} \mathrm{H}_{31}$ & 0.43 & 43 & 43 & $39+63$ \\
\hline 8 & 25000 & $\mathrm{HOOC}^{\mathrm{br}} \mathrm{C}_{15} \mathrm{H}_{31}$ & 0.43 & 43 & 38 & \\
\hline 9 & 5000 & $\mathrm{HOOC}^{\mathrm{br}} \mathrm{C}_{15} \mathrm{H}_{31}$ & 0.43 & 43 & 38 & \\
\hline
\end{tabular}

${ }^{a}$ Reaction time $18-21 \mathrm{~h}$. Temperature: $140{ }^{\circ} \mathrm{C}$. Membrane pump vacuum (ca. 20 mbar). ${ }^{b}$ With increasing degree of amidation, the change of elemental composition with degree of amidation decreases. Thus, for higher degrees of amidation (ca. $>60 \%)$ determination of the degree of amidation from elemental analysis is not feasible due to a high experimental error.

Scheme 2. Activation of Palmitic Acid with Carbonyldiimidazole (CDI) and Reaction with Polyethylenimine

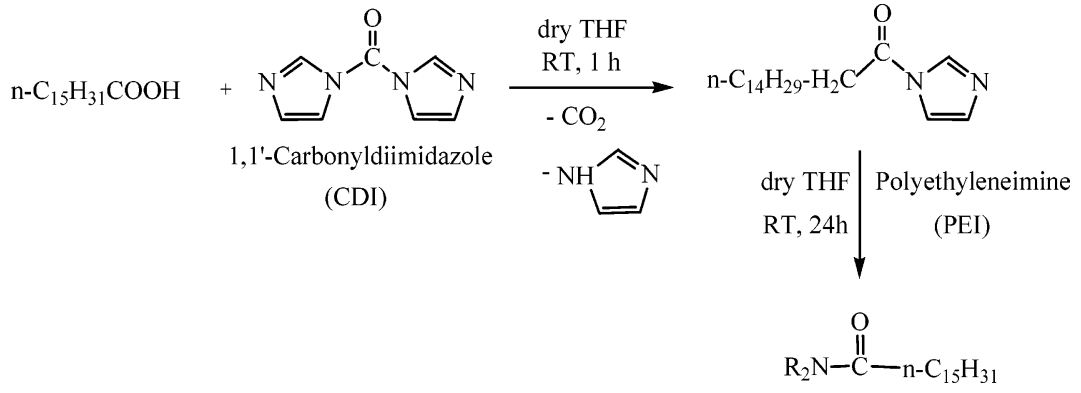

monitored by periodically drawing samples and analyzing them by ${ }^{1} \mathrm{H}$ and ${ }^{13} \mathrm{C}$ NMR spectroscopies. By contrast to general textbook reactivities, reaction of the primary amine was an order of magnitude faster, with

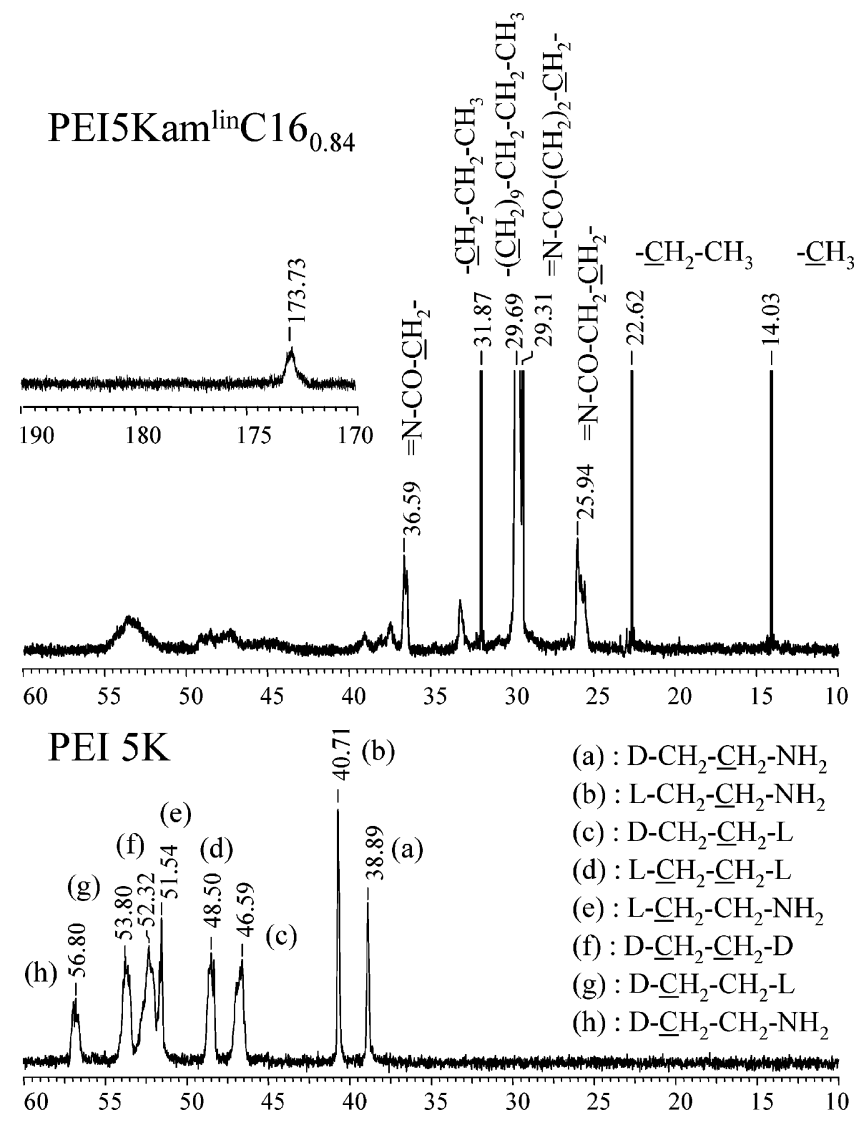

Figure 3. ${ }^{13} \mathrm{C}$ NMR spectra of partially amidated polyethylenimine (PEI5Kam $\left.{ }^{\text {lin }} \mathrm{C} 6_{0.84}\right)$ and the starting polyethylenimine (for full assignments cf. text; for assignment of unmodified polyethylenimine, cf. ref 12).
$50 \%$ conversion after $1 \mathrm{~h}$. This confirms that also in the simple solvent-free bulk amidation with carboxylic acid or esters, which is particularly well suited for carrying out reactions on a larger scale; the primary amine end groups can be reacted relatively selectively. Signals at 33, 37.5, and $39 \mathrm{ppm}$ (weaker) can be assigned to D- $\mathrm{CH}_{2} \mathrm{CH}_{2} \mathrm{NH}(\mathrm{CO}) \mathrm{R}$ and the corresponding carbon atom in the amidation products of the $\mathrm{L}-\mathrm{CH}_{2} \mathrm{CH}_{2} \mathrm{NH}_{2}$ moieties.

All of the above PEI-amides are waxy, brittle solids at room temperature due to the crystallization of the alkyl side chains. Introduction of an increased number of alkyl chains per core-shell molecule for a given degree of amidation would enable the use of shorter chains for a given mass ratio PEI core/hydrocarbon shell. Hereby, side-chain crystallization of the alkyl chains can be reduced. This can be of interest e.g. for film formation on solid substrates or for increasing the solubility in hydrocarbon solvents, such as aliphatic substrates of catalytic reactions. As previously discussed, amidation with linear esters was found to result in complete and selective conversion of the primary amine groups, at the same time excess ester can be removed easily. The branched ester ethyl 2-hexyldecanoate was found to be entirely unreactive toward PEI under the same conditions: the unreacted PEI was recovered after heating with 1 equiv of ester to 140 ${ }^{\circ} \mathrm{C}$ under vacuum overnight. By contrast, the branched acid reacted (Table 1; entries 8 and 9). Reacting PEI and 0.43 equiv of 2 -hexyldecanoic acid at $140{ }^{\circ} \mathrm{C}$ under vacuum for $18 \mathrm{~h}$, the degree of amidation was found to be $43 \%$. All primary amine end groups appear to be converted, as evidenced by ${ }^{13} \mathrm{C}$ NMR spectroscopy. The polymer obtained is a viscous liquid, which does not display any melt transition by DSC (range -100 to $\left.150{ }^{\circ} \mathrm{C}\right)$.

Solution Structure. Regarding the concept of a confined space provided by the core of a single am- 


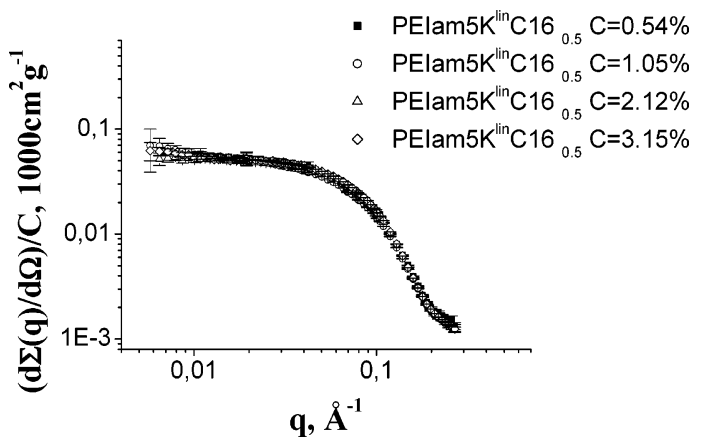

Figure 4. Small-angle neutron scattering intensity for an amidated polyethylenimine with a degree of amidation of $50 \%$ (PEIam5K ${ }^{\operatorname{lin}} \mathrm{C}_{16} 6_{0.5}$ ) in $\mathrm{C}_{6} \mathrm{D}_{6}$ normalized by concentration.

Table 2. Apparent Radius of Gyration $\left(\boldsymbol{R}_{\mathrm{g}}\right)$ Determined by Small-Angle Neutron Scattering (Guinier Approximation) of Amidated Polyethylenimine Samples with Different Core Molecular Weights and Different Degrees of Amidation at Different Concentrations

\begin{tabular}{|c|c|c|}
\hline polymer type & $\begin{array}{l}\text { concn } \\
\left(\mathrm{g} \mathrm{L}^{-1}\right)\end{array}$ & $\begin{array}{l}R_{\mathrm{g}}(\mathrm{nm}) \text { from Guinier } \\
\text { approximation }\end{array}$ \\
\hline \multirow[t]{4}{*}{ PEI5Kam ${ }^{\operatorname{lin} C 16_{0.5}}$} & 5.1 & $2.1 \pm 0.1$ \\
\hline & 10 & $2.8 \pm 0.2$ \\
\hline & 20 & $2.3 \pm 0.3$ \\
\hline & 30 & $2.0 \pm 0.2$ \\
\hline \multirow[t]{4}{*}{ PEI25Kam ${ }^{\operatorname{lin}} \mathrm{C} 16_{0.5}$} & 9.5 & $5.2 \pm 0.3$ \\
\hline & 19 & $5.0 \pm 0.3$ \\
\hline & 28.5 & $4.7 \pm 0.2$ \\
\hline & 38 & $4.6 \pm 0.2$ \\
\hline \multirow[t]{2}{*}{ PEI25Kam ${ }^{\operatorname{lin}} \mathrm{C} 16_{0.9}$} & 9.5 & $5.1 \pm 0.2$ \\
\hline & 19 & $4.6 \pm 0.2$ \\
\hline
\end{tabular}

phiphilic molecule, which can be employed as a "nanoreactor", the solution structure of the polymer is decisive. In view of the high flexibility of the branched scaffold, molecules can also aggregate to large micellelike structures. To this end, SANS studies were carried out.

The structure of two polymers obtained from different molecular weight cores, but having the same degree of amidation, were investigated by small-angle neutron scattering. Solutions of PEIam5 $\mathrm{K}^{\operatorname{lin}} \mathrm{C} 16_{0.5}$ and PEIam25K ${ }^{\operatorname{lin}} \mathrm{C} 16_{0.5}$ at various concentrations in $\mathrm{C}_{6} \mathrm{D}_{6}$ were analyzed.

The scattering curves of the normalization of the scattering intensity by polymer concentration obtained for PEIam5K ${ }^{\text {lin }} \mathrm{C} 16_{0.5}$ are shown in Figure 4.

An overlap of the different curves indicates that interaction effects are negligible at these concentrations. The scattering intensity at zero angle, $\mathrm{d} \Sigma(0) / \mathrm{d} W$, and the radius of gyration $\left(R_{\mathrm{g}}=\left\langle s^{2}\right\rangle_{z}{ }^{1 / 2}\right)$ of the polymers were obtained within the Guinier approximation, and the weight-average molar mass was calculated from the intensity at zero scattering angle as $M_{\mathrm{w}}=11.9 \pm$ $0.4 \mathrm{~kg} \mathrm{~mol}^{-1}$, which fits reasonably with $M_{\mathrm{w}}=16.1 \mathrm{~kg}$ $\mathrm{mol}^{-1}$ calculated from the molecular weight corresponding to the reacted alkyl chains added to the core molecular weight. The radius of gyration was $2.3 \pm$ $0.3 \mathrm{~nm}$.

The radius of gyration of $\mathrm{PEIam} 25 \mathrm{~K}^{\operatorname{lin}} \mathrm{C} 16_{0.5}$ at various concentration was also calculated. As for PEIam5K ${ }^{\operatorname{lin}} \mathrm{C} 16_{0.5}$, the apparent radius of gyration changes only slightly upon increasing the concentration, which indicates that aggregation is negligible (see Table 2).

Figure 5 displays a comparison of the data obtained for two samples of different degrees of amidation (PEIam5K ${ }^{\operatorname{lin}} \mathrm{C} 16_{0.5}$ and PEIam25K ${ }^{\operatorname{lin}} \mathrm{C} 16_{0.9}$ ). The data

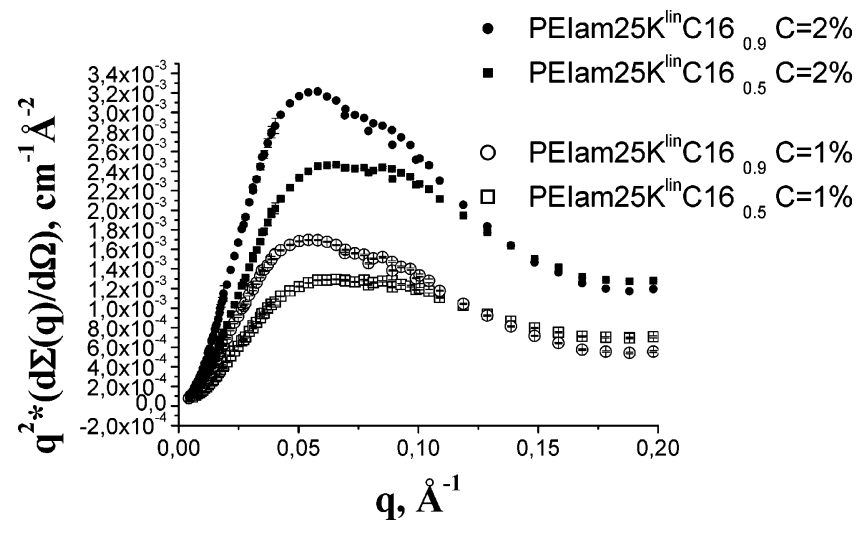

Figure 5. Kratky plot of small-angle neutron scattering data of amidated polyethylenimine samples of different degrees of amidation.

are shown in a Kratky representation which provides information on the polymer shape. The general shape of the curves is the same for all data sets and is typical of hyperbranched polymers. ${ }^{12,17}$ The $q$-position of the maximum is correlated with the mean radius of gyration as $q_{\max } R_{\mathrm{g}}=\sqrt{6}$ and slightly shifted to lower $q$ with increasing degree of derivatization.

\section{Summary and Conclusions}

Amphiphilic macromolecules with a polar hyperbranched polyamine core and an apolar hydrocarbon periphery can be prepared conveniently from polyethylenimine (PEI) and carboxylic acid derivatives. Amidation of PEI with palmitic acid or the methyl ester proceeds up to $84 \%$ degree of amidation $\left(140{ }^{\circ} \mathrm{C}\right.$, vacuum), $100 \%$ degree of amidation corresponding to complete conversion of all primary amine end groups to the secondary amide and of all secondary amine linear units to the tertiary amide. The primary amine end groups react preferentially and rather selectively under these conditions, such that the "periphery" of the core is substituted preferentially. With carbonyldiimidazole (CDI)-activated acids nearly complete conversion of all primary amine end groups and secondary amine linear units can be achieved (THF, room temperature); with a corresponding limited amount of CDI the end groups can be amidated selectively. The final products of these reactions are free of any unreacted carboxylic acid or other impurities according to ${ }^{1} \mathrm{H}$ and ${ }^{13} \mathrm{C}$ NMR spectroscopies. Crude products can optionally be purified by pressure ultrafiltration washing with a toluene/ amine solution. Side-chain crystallization is observed (DSC), which can be supressed entirely employing branched alkyl moieties with 2-hexyldecanoic acid as the amidating agent.

Solution structures of three different samples, PEIam5K ${ }^{\operatorname{lin}} \mathrm{C} 16_{0.5}, \quad$ PEIam25K ${ }^{\text {lin }} \mathrm{C} 16_{0.5}, \quad$ and PEIam25K ${ }^{\text {lin }}$ C16 0.9 , were studied by SANS employing Guinier analysis. In $\mathrm{C}_{6} \mathrm{D}_{6}$ apparent radii of gyration of 2 and $5 \mathrm{~nm}$ were observed for the samples based on the $5 \mathrm{~K}$ and $25 \mathrm{~K}$ PEI core, respectively. These sizes and their observed independence of concentration in the range of $5-40 \mathrm{~g} \mathrm{~L}^{-1}$ indicate the presence of nonaggregated unimolecular inverted micelles.

\section{Experimental Section}

Materials and General Considerations. THF was distilled from sodium under argon. P.A. grade dry methanol and $>99.5 \%$ toluene were employed without further purification. 
Polyethylenimine (BASF Lupasol; $M_{\mathrm{w}} 5000 \mathrm{~g} \mathrm{~mol}^{-1}, M_{\mathrm{w}} / M_{\mathrm{n}}=$ 1.1 and $\left.M_{\mathrm{w}} 25000 \mathrm{~g} \mathrm{~mol}^{-1}, M_{\mathrm{w}} / M_{\mathrm{n}}=2.5\right)^{8 \mathrm{a}}$ was dried prior to use by stirring for several days at $100{ }^{\circ} \mathrm{C}$ under vacuum $(<1$ mbar). Tributylamine $(>98.5 \%)$, palmitic acid (90\%), and 2-hexyldecanoic acid (96\%) were obtained from Aldrich. Methyl palmitate $(97 \%)$ was obtained from Fluka.

${ }^{1} \mathrm{H}$ and ${ }^{13} \mathrm{C}$ NMR spectra were recorded on a Bruker ARX 300 instrument at 300 and $75 \mathrm{MHz}$, respectively. Inverse gated ${ }^{13} \mathrm{C}$ NMR spectra were recorded in the presence of a few crystals of chromium(III) acetylacetonate. Differential scanning calorimetry (DSC) was performed on a Perkin-Elmer DSC 7 or on a Pyris 1 DSC. The instrument was calibrated with indium and cyclohexane. The polymers were heated in the temperature range of -100 to $150{ }^{\circ} \mathrm{C}$ at a heating rate of $10 \mathrm{~K} / \mathrm{min}$. The DSC data reported are second heat. $T_{\mathrm{m}}$ given are peak temperatures. Samples for elemental analysis were dried for at least $48 \mathrm{~h}$ at $120^{\circ} \mathrm{C}$ in vacuo ( $<0.8$ mbar) and analyzed by the Institute of Organic Chemistry of Freiburg University on a Elementar Vario EL instrument.

SANS Measurements. Small-angle neutron scattering experiments were performed with the SANS1 instrument at the FRG1 research reactor at the GKSS Research Center, Geesthacht, Germany. ${ }^{18}$ The neutron wavelength was $8.1 \AA$ with a wavelength resolution of $10 \%$ (fwhm). A range of scattering vectors $0.007<q<0.25 \AA^{-1}$ was obtained using three sampleto-detector distances $(0.7-7 \mathrm{~m}), q=(4 \pi / \lambda) \sin (\theta / 2)(l$ is the wavelength and $q$ is the scattering angle). Samples were kept at $25 \pm 1{ }^{\circ} \mathrm{C}$ in quartz cuvettes with a path length of $1 \mathrm{~mm}$. Raw spectra were corrected for backgrounds from solvent, sample cell, and other sources by conventional procedures. The two-dimensional isotropic scattering spectra were azimuthally averaged, converted to an absolute scale, and corrected for detector efficiency by dividing by the incoherent scattering spectrum of pure water, which was measured with a $1 \mathrm{~mm}$ cell.

Amidation in Bulk with Acid or Ester. Preparation of PEI5Kam ${ }^{\text {lin }}$ C16 0.43 . PEI $(2.0 \mathrm{~g}, 46 \mathrm{mmol} \mathrm{N}$ groups $=$ repeat units) and palmitic acid (3.6 g, $14 \mathrm{mmol}$ ) were heated at 140 ${ }^{\circ} \mathrm{C}$ under vacuum in a $250 \mathrm{~mL}$ glass reactor equipped with a mechanical stirrer, a reflux condensor connected with a membrane vacuum pump, and a thermocouple dipping into the reaction mixture. After $21 \mathrm{~h}$, the mixture was cooled under argon. After purification by ultrafiltration, the polymer was dried at $120{ }^{\circ} \mathrm{C}$ under vacuum for 2 days. The pure polymer was obtained with a yield of $60 \%$.

${ }^{1} \mathrm{H} \quad \mathrm{NMR}\left(\mathrm{CDCl}_{3}\right): \quad \delta$ (ppm) 0.8 (t, $\left.\mathrm{CH} 3\right), 1.2 \quad(\mathrm{~m}$, $\left.\mathrm{CH}_{3}-\left(\mathrm{CH}_{2}\right)_{12}-\right), 1.6\left(-\mathrm{CH}_{2}-\mathrm{CH}_{2}-\mathrm{CO}\right), 2.1\left(-\mathrm{CH}_{2}-\mathrm{CH}_{2}-\mathrm{CO}\right)$, $2.3-3.6\left(\mathrm{~m}, \mathrm{CH}_{2}-\mathrm{NH}-\mathrm{CH}_{2}-\mathrm{CH}_{2}-\mathrm{NH}-\mathrm{CH}_{2},-\mathrm{CH}_{2}-\mathrm{CH}_{2}-\right.$ $\mathrm{NH}-\mathrm{CO},-\mathrm{NH}-$ ).

${ }^{13} \mathrm{C} \mathrm{NMR}\left(\mathrm{CDCl}_{3}\right): \delta(\mathrm{ppm}) 14.0\left(\mathrm{CH}_{3}\right), 22.6\left(\mathrm{CH}_{3}-\mathrm{CH}_{2}\right), 25.9$ $\left(\mathrm{CH}_{2}-\mathrm{CH}_{2}-\mathrm{CO}\right), 29.3\left(\mathrm{CH}_{2}-\left(\mathrm{CH}_{2}\right)_{2}-\mathrm{CO}\right), 29.7\left(-\left(\mathrm{CH}_{2}\right)_{9}-\right.$ $\left.\left(\mathrm{CH}_{2}\right)_{3}-\mathrm{CO}\right), 31.9\left(\mathrm{CH}_{3}-\mathrm{CH}_{2}-\mathrm{CH}_{2}\right), 36.6\left(\mathrm{CH}_{2}-\mathrm{CO}\right), 33-55$ (br. $\left.\mathrm{NCH}_{2} \mathrm{CH}_{2} \mathrm{~N}\right), 173.6(\mathrm{CO})$.

Amidation with CDI Activation. The reaction was performed under argon. To a 1,1'-carbonyldiimidazol suspension in dry THF ( $6.6 \mathrm{~g}, 41 \mathrm{mmol}$ in $50 \mathrm{~mL}$ ) was added 1 equiv of acid (10.4 g, $41 \mathrm{mmol})$. After a few minutes, release of carbon dioxide was observed and monitored by means of a bubbler connected to the flask. The obtained solution, which was clear and colorless, was stirred $1 \mathrm{~h}$ at room temperature and transferred to a flask containing a mixture of PEI ( $2.5 \mathrm{~g}, 58$ mmol of repeat units, of which $41 \mathrm{mmol}$ primary and secondary amine) and $50 \mathrm{~mL}$ of dry THF. The suspension was stirred for $24 \mathrm{~h}$ and finally refluxed for $1 \mathrm{~h}$. The crude product was purified by ultrafiltration and dried at $120^{\circ} \mathrm{C}$ under vacuum for 2 days, and the pure polymer was obtained with a yield of $78 \%$.

Ultrafiltrations were carried out in a magnetically stirred (500 rpm) custom-made steel cell of $50 \mathrm{~mL}$ volume. After transfer of the polymer solution to the cell, solvent was supplied continuously to the cell by means of a dosing pump, sustaining a transmembrane pressure of ca. 10 bar. A Koch MPF-50 membrane (nominal MWCO 700) was utilized. Typically $10 \mathrm{wt} \%$ polymer solutions (5 g of polymer) were employed. Flow rates were around $30 \mathrm{~L} \mathrm{~m}^{2} \mathrm{~h}^{-1}$. Polymers were purified by ultrafiltration in toluene, typically washing with the 10-fold cell volume. For removal of excess carboxylic acid, the polymer was first washed with toluene, then a $10 \mathrm{vol} \%$ solution of tributylamine in toluene, and finally with toluene to remove the amine. The composition of the filtrate was frequently monitored by evaporating a fraction collected to dryness, gravimetically determining the amount of solute, and identifiying its composition by NMR spectroscopy. After the filtration, the retentate was recovered from the cell and the solvent removed in vacuo. Purified products were isolated in $60-90 \%$ yield.

Acknowledgment. Financial support by the Volkswagen-Foundation (Schwerpunkt Komplexe Materialien: Verbundprojekte in den Natur-, Ingenieur- und Biowissenschaften) is gratefully acknowledged. S.M. is indebted to the Fonds der chemischen Industrie and the Eugen-Graetz-Foundation for financial support. We thank A. Rossel for construction of ultrafiltration cells.

\section{References and Notes}

(1) (a) Hecht, S.; Frechet, J. M. Angew. Chem., Int. Ed. 2001 40, 74-90. (b) Haag, R. Angew. Chem., Int. Ed. 2004, 43, $278-282$.

(2) (a) Coelfen, H. Macromol. Rapid Commun. 2001, 22, 219252. (b) Crooks, R. M.; Zhao, M.; Sun, L.; Chechik, V.; Yeung, L. K. Acc. Chem. Res. 2001, 34, 181-190. (c) Sauer, M.; Meier, W. In Colloids and Colloid Assemblies; Caruso, F., Ed.; WileyVCH: Weinheim, 2004; pp 150-174.

(3) (a) Ng Cheong Chan, Y.; Craig, G. S. W.; Schrock, R. R. Cohen, R. E. Chem. Mater. 1992, 4, 885-894. (b) Saito, R.; Okamura, S.; Ishizu, K. Polymer 1992, 33, 1099-1101. (c) Antonietti, M.; Wenz, E.; Bronstein, L.; Seregina, M. Adv. Mater. 1995, 7, 1000-1005. (d) Spatz, J. P.; Roescher, A.; Moeller, M. Adv. Mater. 1996, 8, 337-340. (e) Moffitt, M.; Eisenberg, A. Chem. Mater. 1995, 7, 1178-1184. (f) Moeller, M.; Spatz, J. P. Curr. Opin. Colloid Interface Sci. 1997, 2 , 177-187. (g) Bronstein, L.; Antonietti, M.; Valetsky, P. Nanoparticles and Nanostructured Films; Fendler, J. H., Ed.; Wiley-VCH: Weinheim, 1998; pp 145-171.

(4) (a) Kurihara, K.; Fendler, J. H. J. Am. Chem. Soc. 1983, 105 6152-6153. (b) Kurihara, K.; Fendler, J. H.; Ravet, I.; Nagy, J. B. J. Mol. Catal. 1986, 34, 325-335. (c) Toshima, N.; Takahashi, T.; Hirai, H. Chem. Lett. 1986, 35-38. (d) Toshima, N.; Takahashi, T.; Hirai, H. Chem. Lett. 1987, 1031-1034.

(5) (a) Sunder, A.; Krämer, M.; Hanselmann, R.; Mülhaupt, R.; Frey, H. Angew. Chem., Int. Ed. 1999, 38, 3552-3554; Angew. Chem. 1999, 111, 3758-3761. (b) Stiriba, S. E.; Kautz, H.; Frey, H. J. Am. Chem. Soc. 2002, 124, 9698-9699.

(6) Garamus, V. M.; Maksimova, T.; Richtering, W.; Kautz, H.; Frey, H.; Schlotterbeck, U.; Mecking, S. Macromolecules 2004, 37, 8394-8399.

(7) (a) Mecking, S.; Thomann, R.; Frey, H.; Sunder, A. Macromolecules 2000, 33, 3958-3960. (b) Sablong, R.; Schlotterbeck, U.; Vogt, D.; Mecking, S. Adv. Synth. Catal. 2003, 3, 333-336 (c) Schlotterbeck, U.; Aymonier, C.; Thomann, R.; Hofmeister, H.; Tromp, M.; Richtering, W.; Mecking, S. Adv. Funct. Mater. 2004, 14, 999-1004. (d) Schlotterbeck, U. Ph.D. Thesis, Freiburg University, 2004.

(8) (a) Lupasol Product Range, Preliminary Technical Information, BASF. (b) Pfau, A.; Schrepp, W.; Horn, D. Langmuir 1999, 15, 3219-3225.

(9) Aymonier, C.; Schlotterbeck, U.; Antonietti, L.; Zacharias, P. Thomann, R.; Tiller, J.; Mecking, S. Chem. Commun. 2002, $3018-3019$

(10) Garamus, V. M.; Maksimova, T.; Richtering, W.; Aymonier, C.; Thomann, R.; Antonietti, L.; Mecking, S. Macromolecules 2004, 37, 7893-7900.

(11) Polyelectrolytes; Dautzenberg, H., Jaeger, W., Kötz, J., Philipp, B.,Seidel, C., Stscherbina, D., Eds.; Hanser: Munich, 1994.

(12) Lukovin, G. M.; Pshezhetsky, V. S.; Murtazaeva, G. A. Eur. Polym. J. 1973, 9, 559-565. 
(13) Hölter, D.; Burgath, A.; Frey, H. Acta Polym. 1997, 48, 3035.

(14) Decker, J.; Geisler, B.; Paciello, R.; Mahr, N.; Vos, H.; Zeller, E.; Röper, M. WO99/36382 (BASF).

(15) Stevelmans, S.; van Hest, J. C. M.; Jansen, J. F. G. A.; van Boxtel, D. A. F. J.; de Brabander-van den Berg, E. M. M.; Meijer, E. W. J. Am. Chem. Soc. 1996, 118, 73987399 .

(16) The formation of a homogeneous mixture is by no means indicative of the degree of the amidation reaction, as it may also be due to salt formation of the PEI with the carboxylic acid.

(17) deLuca, E.; Richards, R. W.; Grillo, I.; King, S. M. J. Polym. Sci., Part B: Polym. Phys. 2003, 41, 1352-1361.

(18) Stuhrmann, H. B.; Burkhardt, N.; Dietrich, G.; Jünemann, R.; Meerwinck, W.; Schmitt, M.; Wadzack, J.; Willumeit, R. Zhao, J.; Nierhaus, K. H. Nucl. Instrum. Methods 1995, A356, 133-137. 